\title{
Scale of Auditory Behaviors in the monitoring of acoustically controled auditory training
}

Ana Carolina de Oliveira Sobreira ${ }^{1}$ https://orcid.org/0000-0002-3690-1439

Daniela Gil ${ }^{1}$

https://orcid.org/0000-0002-8647-6813

Universidade Federal de São Paulo UNIFESP - São Paulo, São Paulo, Brasil.

Research support source: Fundação para Pesquisa do Estado de São Paulo FAPESP, number: 2014 / 19827-5.

Conflict of interests: Nonexistent

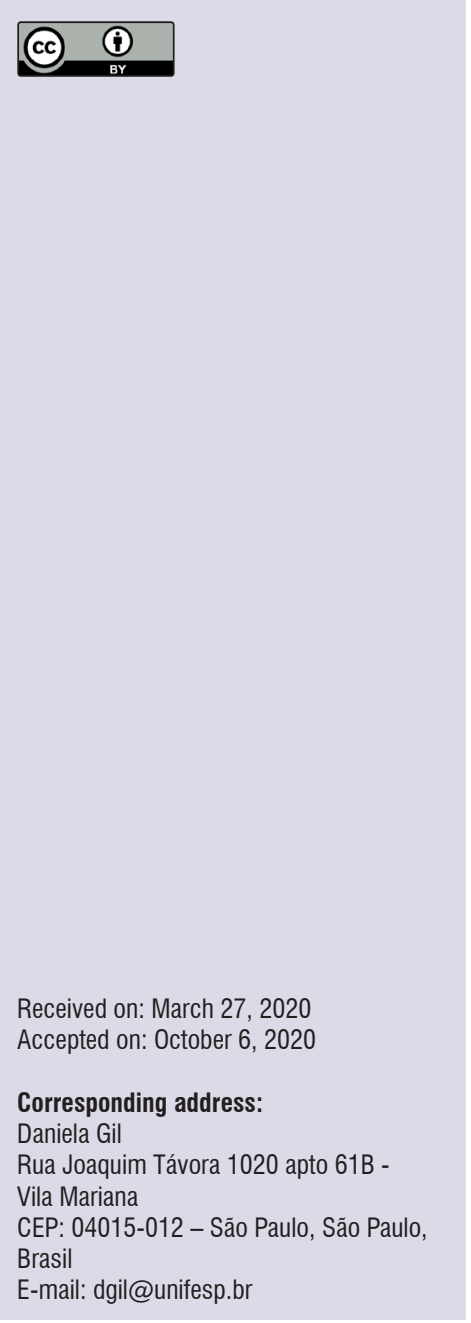

\section{ABSTRACT}

Purpose: to identify the Scale of Auditory Behaviors perception after an acoustically controlled auditory training program.

Methods: 23 individuals of both genders, aged 6 to 15 years, participated in this study. Inclusion criteria: to present auditory thresholds lower than $20 \mathrm{dBHL}$ between 250 and $8000 \mathrm{~Hz}$, type A tympanometry and diagnosis of central auditory processing disorder confirmed by behavioral tests with indication of acoustically controlled auditory training which was performed in ten one-hour sessions. Hearing tests in progressively adverse listening conditions were used. In the first and last session of the acoustically controlled auditory training program, the individuals were submitted to the Scale of Auditory Behaviors. The appropriate statistical tests were applied considering a p-value less than 0.05 .

Results: questions Q1, Q2, Q4, Q7, Q8 and Q11 showed statistically significant results and improvement in behaviors after the acoustically controlled auditory training. On the other hand, questions Q3 and Q10 showed a tendency towards significance and the total score in the post time period increased in relation to the pre-moment, pointing to a statistically significant difference that represents complaint reductions.

Conclusion: the subjective perception of the individuals and their family members could be identified by the application of $S A B$ in the pre and post auditory training, revealing an improvement in auditory and attention behaviors.

Keywords: Audiology; Child Language; Speech, Language and Hearing Sciences; SelfAssessment; Auditory Perception 


\section{INTRODUCTION}

Central auditory processing (CAP) deals with the efficiency and effectiveness of the central nervous system related to the information received via the sense of hearing. When this process fails, there is a possibility of central auditory processing disorder (CAPD), which can result in changes in communication and /or learning ${ }^{1-3}$. Characteristic behaviors of individuals with CAPD are alterations in oral communication or in the use of grammatical rules, as inversions of graphemes, changes in the notion of laterality, agitation, hyperactivity or apathy, impaired auditory memory and difficulty in understanding the acoustic message in noisy environments.

There are several approaches for the treatment of CAPD, with the majority of programs including acoustically controlled auditory training (ACAT) and improved access to the acoustic signal. It also includes the use of language, cognitive and metacognitive strategies, facilitating plasticity and cortical reorganization ${ }^{1-3}$. ACAT needs to be intense and has activities that are challenging to the auditory system. Besides, it must remain interesting enough to maintain the patient's motivation, avoidingfrustration ${ }^{4}$.

Studies have shown that specific ACAT techniques can positively stimulate temporal auditory processes of individuals who have language and learning difficulties. Specific auditory skills can be improved with training and this better performance of the auditory system is directly linked to the ability to modification of the central nervous system ${ }^{5}$. Such ability to reorganize the central nervous system is called neural plasticity and can be defined as neuronal modification based on environmental influences that have repercussions on behavioral changes ${ }^{1}$.

A study ${ }^{6}$ found that the average of correct answers in the behavioral tests (PSI -Pediatric Sentence Identification, speech in noise, non-verbal dichotic and SSW - Staggered Spondaic Word tests) in the CAP evaluation after the ACAT showed a statistically significant difference when comparing initial and final evaluations. The same study revealed that $63.3 \%$ of the children presented results of CAP within normal limits after the program, demonstrating that it was effective in the rehabilitation of altered auditory skills.

In Brazil, there are still no specific normalized and published instruments for self-assessment after ACAT. International questionnaires are usually used for other purposes, such as to measure the benefit with hearing aids or general quality of life questionnaires, for example the Abbreviated Profile of Hearing Aid Benefit $(\mathrm{APHAB})^{7}$ and the Hearing Handicap Inventory for the Elderly $(\mathrm{HHIE})^{8}$. It is important the use especial scales for CAPD, considering the specificities of this disorder.

A study ${ }^{9}$ in Brazil used a questionnaire to monitor the results rendered by ACAT in adolescents. In this study, the Fisher's auditory problems checklist for auditory processing evaluation (QFISHER) was used, proving to be effective to monitor auditory behavior before, during and after auditory training.

According to recent results of a systematic review ${ }^{10}$, the only instrument for Brazilian Portuguese is the Auditory Processing Domains Questionnaire (APDQ) ${ }^{11}$. It has $100 \%$ sensitivity and specificity and therefore is the most suitable instrument for application in clinical practice and researches. One study ${ }^{12}$ used the translated, back-translated and culturally equivalent versions of the questionnaire in a group of school-age children without CAPD. The total score of the original questionnaire is 208 points and the translated version obtained an average of 199.2 points - a score close to the original. Another study ${ }^{13}$ applied the translated and validated version to school-aged individuals with ACAT, obtaining an average of 92.6 points. The researchers stated that there was a statistically significant difference between the group with CAPD, subject of the study, and the group without CAPD, evaluated in the translation study. Therefore, they suggested that such an instrument could be a potential tool to evidence individuals at risk for CAPD.

The Post Training Exit Questionnaire (PTEQ) ${ }^{14}$ was developed with the main objective of investigating the benefits of an AT program and its repercussions on the hearing experiences of patients submitted to this intervention. The subjects included in the original study (78 hearing aid users and 15 cochlear implant users) aged between 18 and 89 years old, underwent a six-week AT program, with hour-long sessions, twice a week. After training, the subjects answered the PTEQ questionnaire. The questions in this instrument relate to the improvement in situations of adverse listening, understanding of syllables, sentences, contexts and the appreciation of the AT program. The response possibilities ranged from 1 (very little) to 7 (too much). Study participants reported improvements in their speech recognition skills and in their self-confidence as a result of participating in the training.

Scale of Auditory Behaviors $(\mathrm{SAB})^{15}$ was an instrument developed to be used as a screening tool for CAPD in school children (10 to 13 years old) and 
contains questions related to general and auditory behavior, speech, attention and academic performance. According to the authors of this questionnaire, it is possible to detect signs of CAPD and/or the need for a more comprehensive investigation based on its application.

There are evidences that ACAT is effective in the (re) habilitation of CAPD when measuring and comparing pre and post ACAT with behavioral and electrophysiological tests. Besides, it is important to evaluate patients who underwent interventions and their evolution. They can report behavioral changes mainly related to self-confidence in communication in adverse hearing situations, speech understanding in unfavorable environments, improvement in academic and / or professional self-esteem performance and others.

Considering the patients and their families' point of view are extremely important in the rehabilitation process the aim of this study is to identify the subjective perception of individuals and their families after an ACAT, using the Scale of Auditory Behaviors (SAB).

\section{METHODS}

This study is an observational cross-sectional study and was submitted to the Research Ethics Committee of Universidade Federal de São Paulo - UNIFESP, SP, Brazil, protocol 990,433. It was carried out at the Central Auditory Processing Clinic of the Speech Therapy and Audiology Department at UNIFESP.

All participants and their guardians were informed about the nature of the research, its objectives, methods and procedures. They signed the consent form for voluntary participation in the study.

Before the collection started, the subjects were submitted to the following procedures: pure tone audiometry, speech audiometry, immittance testing and behavioral assessment of central auditory processing. To eligible participate in this study, individuals had hearing thresholds lower than $20 \mathrm{dBHL}$, between 250 and $8000 \mathrm{~Hz}^{16}$, tympanometry with type A curves, diagnosis of CAPD confirmed by behavioral tests, alterations in at least two tests and indication of ACAT. They should have not been submitted to speech therapy or ACAT before. The time between the diagnosis of CAPD and the beginning of ACAT was approximately one month to all individuals. Exclusion criteria were syndromes of any nature, as psychological, psychiatric and cognitive disorders that were evident and / or diagnosed. Based on these criteria, 23 volunteers of both sexes were selected, aged 6 to 15 years old. All attended school and had complaints related to academic performance, so assuming that individuals with school difficulties coexisting with CAPD stood out in the search for care.

The ACAT program was organized in ten sessions, occurring once a week and lasting between 45 and 60 minutes. The sessions were held in an acoustic booth and the auditory tasks were presented by TDH earphones, $C D$ player and a two-channel audiometer. All tasks were presented in progressively adverse listening conditions, through the variation of the signal-noise ratio from positive (favorable) negative (unfavorable).

\begin{tabular}{|l|}
\hline 1st SESSION - Figure-ground for phrases in both ears + SAB application \\
\hline 2nd SESSION - Figure-ground for words: Listening in the right ear + Figure-ground for non-verbal sounds in the left ear. \\
\hline 3rd SESSION - Figure-ground for words: Listening in the left ear + Figure-ground for non-verbal sounds in the right ear. \\
\hline 4th SESSION - Binaural integration + Speech with noise. \\
\hline 5th SESSION - Auditory Closing (phrases, figures and words) Temporal Aspects - Intensity. \\
\hline 6th SESSION - Temporal aspects - Intensity \\
\hline 7th SESSION - Temporal Aspects - Duration. \\
\hline 8th SESSION - Temporal Aspects - Duration + Frequency. \\
\hline 9th SESSION - Temporal Aspects - Frequency. \\
\hline 10th SESSION - Figure-ground for syllables - Directed Listening and Binaural Integration. \\
\hline
\end{tabular}

Figure 1. Schedule of acoustically controlled auditory training sessions 
In the first ACAT session, participants were subjected to the scheduled activities and the application of SAB (Figure 2), through a single interview with the children and / or their parents or guardians. The latter was asked to help in case of difficulties in understanding and respond appropriately, given the complexity of some questions. Scores were agreed between children and their parents.

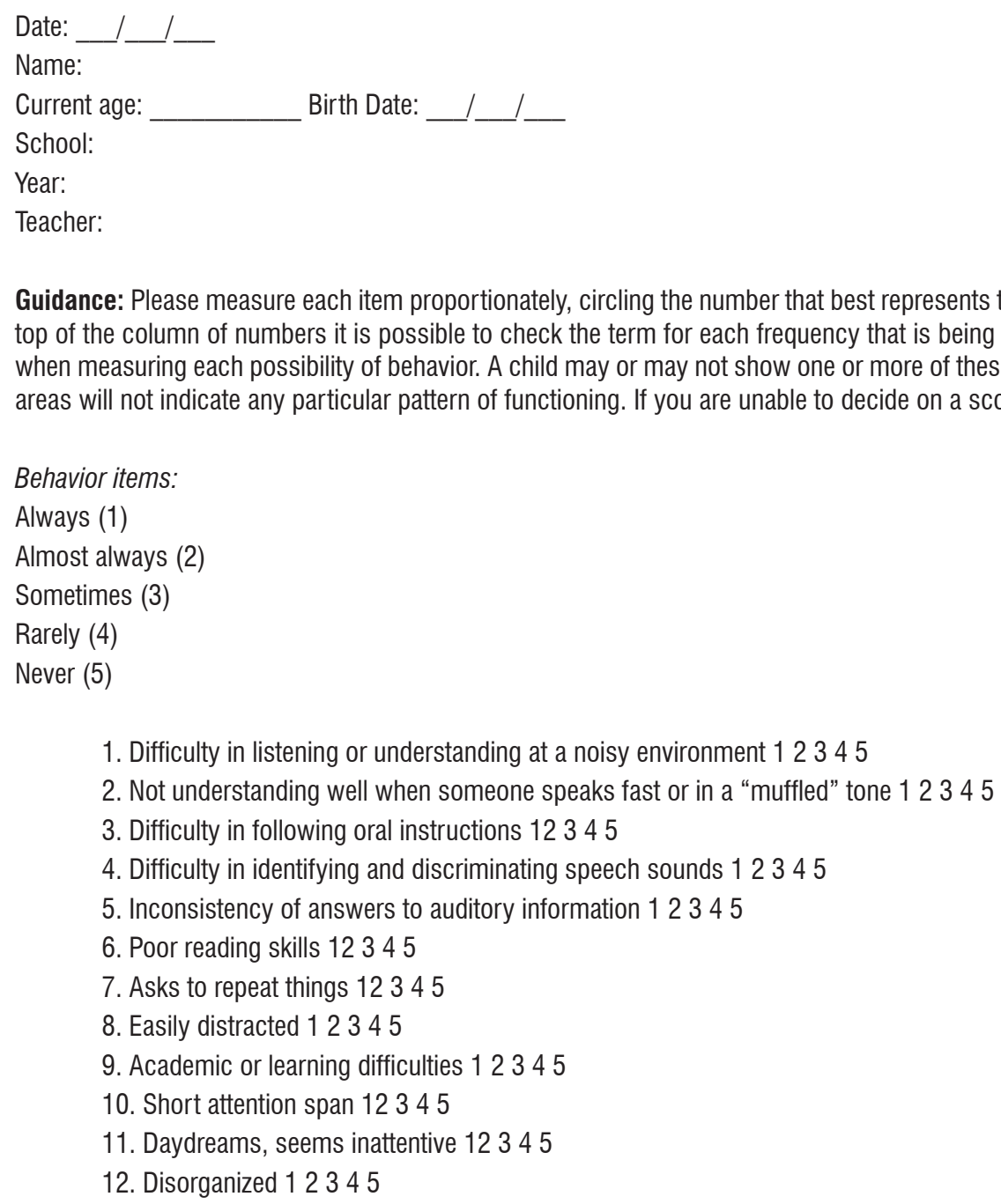

\section{Behavior items:}

Always (1)

Almost always (2)

Sometimes (3)

Rarely (4)

Never (5)

1. Difficulty in listening or understanding at a noisy environment 12345

2. Not understanding well when someone speaks fast or in a "muffled" tone 12345

3. Difficulty in following oral instructions 12345

4. Difficulty in identifying and discriminating speech sounds 12345

5. Inconsistency of answers to auditory information 12345

6. Poor reading skills 12345

7. Asks to repeat things 12345

8. Easily distracted 12345

9. Academic or learning difficulties 12345

10. Short attention span 12345

11. Daydreams, seems inattentive 12345

12. Disorganized 12345

Guidance: Please measure each item proportionately, circling the number that best represents the behavior of the child you are analyzing. At the top of the column of numbers it is possible to check the term for each frequency that is being observed. Please consider these terms carefully when measuring each possibility of behavior. A child may or may not show one or more of these behaviors. A high measurement in one or more areas will not indicate any particular pattern of functioning. If you are unable to decide on a score for a particular item, use your best judgment.

Figure 2. Scale of Auditory Behaviors - $S A B^{9}$

SAB is made up of 12 questions related to day-today events. The one that occurs very frequently is assigned a value of 1.0; the one that occurs almost always receives a value of 2.0; the one that sometimes occurs scores 3.0. Sporadic people received 4.0 and those who never occur 5.0. The values are added up, resulting in a final score that can vary from 12 to 60 points. In the last training session, the CAP's behavioral reassessment was performed and the $S A B$ was reapplied.
After data collection, the results were analyzed using descriptive and inferential statistical analysis. In the descriptive analysis, tables were designed with measures for the scores in the questions from Q1 to Q12 and the total score. In the inferential analysis, for all questions and the total score, the non-parametric signal test was used to compare the median scores between the pre and post ACAT moments. This test was used since the assumption of normality for the distribution of scores was not verified. 
The level of significance adopted for all hypothesis tests performed was less than 0.05 (5\%). When the $\mathrm{p}$-value obtained in a hypothesis test was greater than $5 \%$ but less than $10 \%$, the tested hypothesis is not rejected and we conclude that there is not enough statistical evidence to reject it.

\section{RESULTS}

The results obtained in the SAB will be presented since this study intends to identify the perception of improvement measured from the point of view of the patient submitted to ACAT and / or his family, regarding aspects of academic performance, hearing skills and communication.

Table 1 shows the data of the sample's characterization.
The sample consisted mostly of male subjects (56.5\%), aged between 6 to 15 years old (average of 8.9 years old). CAP alteration that most stood out was the abnormality in decoding and non-verbal processes (52.17\%).

The descriptive measures in the tables were calculated for the set of 23 values of questions Q1 to Q12 and the total score, at each time of assessment and for the 23 values of the difference variable. It can be seen that only the average of the difference variable equals to the difference between the average of the values in the post moment and the average of the values in the pre moment, which means that other descriptive measures did not necessarily respect this rule.

Table 2 shows the pre-and post-ACAT comparison $p$-values for each SAB question.

Table 1. Sample characterization according to gender, age and auditory skills altered in pre-training

\begin{tabular}{lccl}
\hline & Gender & Age & Altered hearing skills \\
\hline Case 1 & Male & 9 & Figure-ground for words \\
Case 2 & Male & 15 & Figure-ground for words, complex temporal ordering and temporal resolution \\
Case 3 & Male & 9 & Figure-ground for words, complex temporal ordering, temporal resolution and auditory closure \\
Case 4 & Male & 8 & Figure-ground for words and auditory closure \\
Case 5 & Female & 7 & Figure-ground for words, complex temporal ordering and temporal resolution \\
Case 6 & Female & 9 & Figure-ground for words \\
Case 7 & Male & 7 & Figure-ground for sentences and words and complex temporal ordering \\
Case 8 & Male & 8 & Figure-ground for words, complex temporal ordering and temporal resolution \\
Case 9 & Female & 7 & Figure-ground for sentences and words and temporal resolution \\
Case 10 & Female & 12 & Figure-ground for words, complex temporal ordering, temporal resolution and auditory closure \\
Case 11 & Male & 9 & Figure-ground for words, complex temporal ordering and temporal resolution \\
Case 12 & Male & 8 & Figure-ground for words, complex temporal ordering and temporal resolution \\
Case 13 & Male & 9 & Figure-ground for sentences and words, complex temporal ordering and temporal resolution \\
Case 14 & Male & 9 & Figure-ground for words and complex temporal ordering \\
Case 15 & Male & 8 & Auditory Closure \\
Case 16 & Female & 12 & Figure-ground for sentences and temporal resolution \\
Case 17 & Female & 10 & Figure-ground for words and complex temporal ordering \\
Case 18 & Female & 7 & Figure-ground for words, complex temporal ordering and temporal resolution \\
Case 19 & Female & 10 & Figure-ground for sentences and words, complex temporal ordering and temporal resolution \\
Case 20 & Male & 8 & Figure-ground for words, auditory closure and temporal resolution \\
Case 21 & Female & 9 & Figure-ground for words and complex temporal ordering \\
Case 22 & Female & 9 & Figure-ground for words, complex temporal ordering and auditory closure \\
Case 23 & Male & 6 & Figure-ground for words \\
\hline
\end{tabular}


Table 2. P-values of the signal test to compare the median population scores between the pre and post acoustically controlled auditory training

\begin{tabular}{ccc}
\hline SAB question & P-value \\
\hline Q1 & $0.021^{*}$ \\
Q3 & $0.023^{*}$ \\
Q4 & $0.092 \#$ \\
Q5 & $0.023^{*}$ \\
Q6 & $>0.999$ \\
$Q 7$ & 0.267 \\
Q8 & $<0.001^{*}$ \\
$Q 9$ & $<0.001^{*}$ \\
Q10 & 0.180 \\
Q11 & $0.092 \#$ \\
Q12 & $<0.001^{*}$ \\
\hline Total score & 0.289 \\
\hline
\end{tabular}

Captions: Q1: Difficulty listening or understanding in a noisy environment ; Q2: Do not understand well when someone speaks fast or "muffled"; Q3: Difficulty following oral instructions ; Q4: Difficulty in identifying and discriminating speech sounds ; Q5: Inconsistency of answers to auditory information ; Q6: Poor reading skills ;

Q7: Asks to repeat things ; Q8: Easily distracted ; Q9: Academic or learning difficulties ; Q10: Short attention span; Q11: Daydreams and seems inattentive and Q12: Disorganized .\#: Tendency to significance. *: Statistically significant.

Statistical test: Non-parametric sign test.

It is noted that the differences in the applications of questions Q1, Q2, Q4, Q7, Q8 and Q11 were statistically significant and questions Q3 and Q10 showed a tendency towards significance.

Table 3 and Figure 3 show the values obtained in the total SAB score, in the pre and post ACAT moments.

Table 3 shows that the values of the population medians in the post ACAT evaluation were higher than at the time pre for the total score.
In Figure 3, the answers for the total SAB score are shown, in the pre and post ACAT moments.

It is possible to notice by Figure 2 that the $S A B$ score, in the post ACAT evaluation increased when compared to the pre ACAT evaluation with a statistically significant difference showing improvement of the subjects submitted to the ACAT.

Table 3. Descriptive Statistics for the total score of the Scale of Auditory Behaviors in the Acoustically Controlled Auditory Training pre and post moments

\begin{tabular}{lcccccc}
\hline Moment & N & Mean & SD & Minimum & Median & Maximum \\
\hline Pre & 23 & 28.7 & 7.9 & 16 & 26 & 42 \\
Post & 23 & 35.8 & 7.2 & 22 & 37 & 46 \\
\hline Difference & 23 & 7.1 & 5.4 & 0 & 6 & 20 \\
\hline
\end{tabular}

Captions: N: number of individuals; SD: standard deviation. 


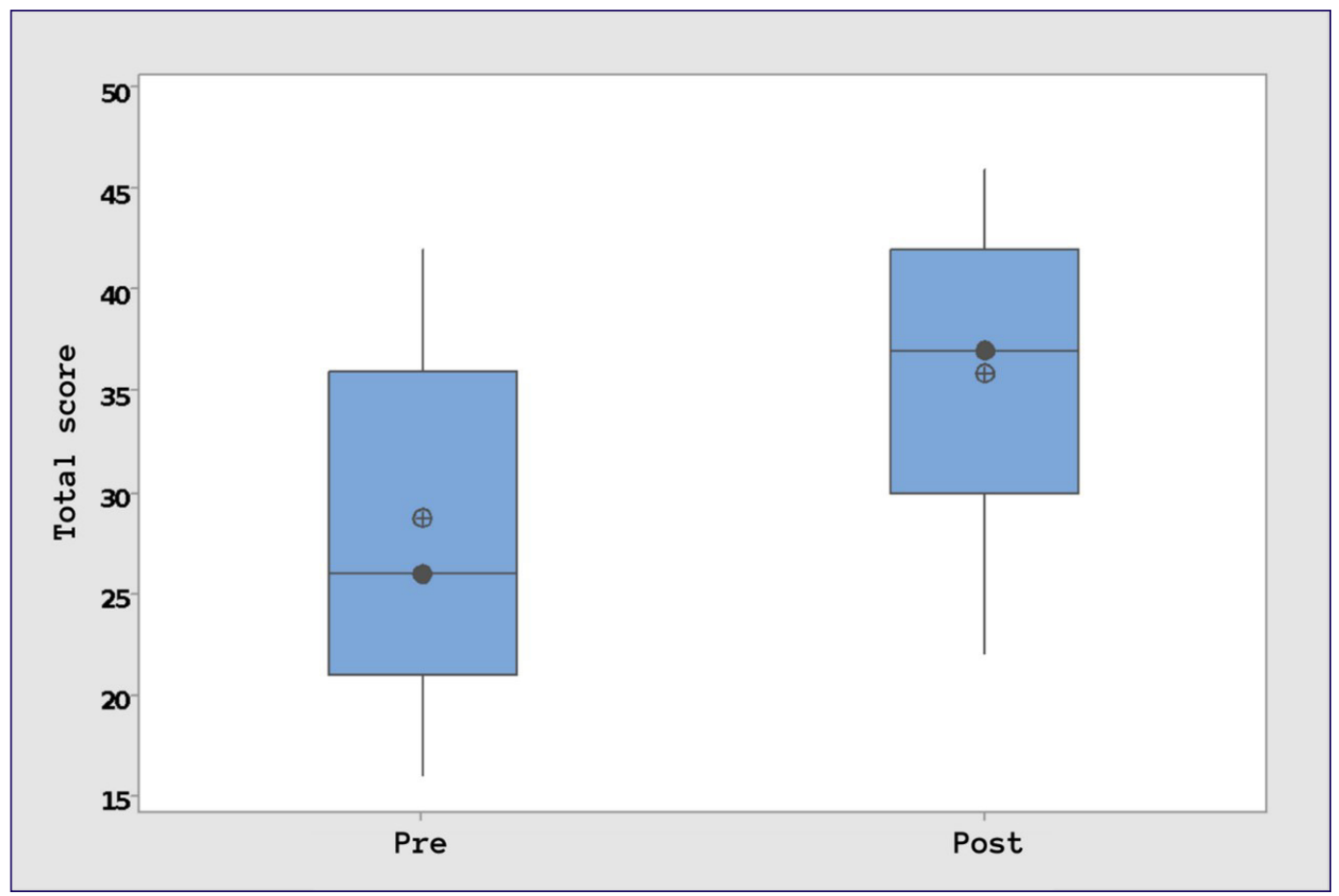

Figure 3. Boxplots of the total score of the Scale of Auditory Behaviors in Acoustically Controlled Auditory Training pre and post moments

\section{DISCUSSION}

This study is relevant to the speech therapy field because it considers the patient's perception regarding the results obtained after ACAT. The relationship between subjective data and the data from objective reassessments (behavioral and electrophysiological tests) allows the improvement of protocols used in the rehabilitation of the patient with CAPD. Besides, it measures how the behavioral modifications could be perceived in the patient's routine in auditory, attentional, academic or behavioral contexts, so the results of ACAT are closer to the reality of the patient.

In Table 1 it was noted that the most altered auditory ability among the subjects was that of auditory figureground. Such alteration corresponds to the difficulty to separate important information to which one should pay attention from competitive noise. This is the auditory ability more redundantly evaluated in the battery of tests used. Alteration in a figure-ground is quite common in CAPD ${ }^{4,17}$, regardless the type of stimulus.

Table 2 shows the occurrence of six questions with a statistically significant difference before and after ACAT, which were: Q1, Q2, Q4, Q7, Q8, Q11; two questions showed tendency to significance: Q3 and Q10; and four showed no trend nor statistically significant differences: Q5, Q6, Q9 and Q12. The questions were grouped into categories to facilitate the discussion.

\section{Auditory category (Q1, Q2, Q3, Q4, Q5 and Q7)}

In questions Q1,"difficulty to hear or understand in a noisy environment"; Q2, "difficulty to understand fast or muffled speech"; Q4, "difficulty to identify and discriminate speech sounds"; and Q7,"request to repeat the speech of the other," an increase in the mean with a statistically significant difference was observed after ACAT. This finding can be compared to the results of previous studies ${ }^{17-21}$, which stated that CAPD can compromise communication in acoustically unfavorable environments and be associated with speech comprehension difficulties.

It is believed that the improvement reported by the interviewees and confirmed by the statistical analysis is relevant because complaints are specifically auditory and are directly related to the objectives of the ACAT, which includes exercises of memory, attention and concentration skills. As all subjects were submitted to the same ACAT program and fully performed it, there was an improvement in the CAP behavioral tests applied after ACAT, which was expected ${ }^{6,11}$.

In question Q3, "difficulty to follow oral instructions," it was noted that the average of responses increased and showed a trend towards significance. Although the results for this question were not statistically significant, it is still possible to verify that patients noticed an improvement in this aspect. However, it is believed 
that the change in this behavior was not so expressive, because it does not depend only on the proper functioning of the auditory system, either peripheral and / or central, but also requires language and cognition aspects ${ }^{15}$ varying regarding the complexity of the instruction presented.

In question Q5 "inconsistency of responses to auditory information," there was no statistically significant difference and in both moments the responses remained the same. Such a finding would not be expected since different studies have pointed out the improvement of receptive language afterACAT ${ }^{6,9}$.

\section{Attention category (Q8, Q10 and Q11)}

In questions Q8, "Easily distracted," and Q11, "daydreams and seem inattentive," the average response increased and there was a statistically significant difference between the moments, showing improvement in these behaviors. Similar results were found in a study ${ }^{22}$ that evaluated children with attention difficulties. There are great scientific evidence ${ }^{22-27}$ that ACAT improves auditory attention, corroborating that perception.

In question Q10, "short attention spans," there was a tendency towards significance, agreeing with previous studies $^{23,27}$ that refer attention levels improvement after a ACAT program. In the interview with the subjects and their parents, this complaint was very frequent, especially when they reported children' situations in the classroom and / or doing homework before being submitted to the ACAT. In the reapplication of the SAB, these complaints were less frequent.

\section{Academic category (Q6 and Q9)}

In questions Q6, "poor reading ability," and Q9, "academic and learning difficulties," there was no statistically significant difference between the applications of the questionnaire. These results disagreed with the findings of other studies ${ }^{5,22}$ that rendered significant improvements in these behaviors after AT. Although some subjects reported improvement in reading ability after ACAT, this was an issue for which significant differences were not expected, as reading is also related to other aspects of language and auditory skills ${ }^{28-32}$. Moreover, a recent study does not correlate CAPD with reading and writing difficulties ${ }^{33}$.

ACAT does not solve reading difficulties, being a complementary tool in the rehabilitation of reading and writing disorders, especially when they can coexist with
CAPD. The ACAT program carried out in the present study sustained predominantly Bottom-up strategies that improve access to auditory information even in adverse environments, as hearing reception. For academic improvements to be evidenced, which also depend on linguistic, phonological and metacognitive skills, Top-down strategies would be the most suitable.

\section{Behavioral category (Q12)}

In question Q12, "disorganized," there were no statistically significant differences between moments. During the application, it was noticed that the family members and the patients themselves had difficulties understanding the questions, even after the examiner participation. This fact may have influenced the response provided and, consequently, the comparison between applications.

\section{Overall score}

Tables 2 and 3 and Figure 3 refer to the total score of the SAB questionnaire before and after ACAT, an increase in the medians was observed in the post ACAT evaluation for questions Q1, Q2, Q4, Q7, Q8, Q11 and for the total score, showing a statistically significant difference for half of the questions proposed in the instrument. For the total score, the median in pre time is 26 and post time 37 . In the analysis proposed by the authors who developed the SAB questionnaire, a score of 56 points indicates that individuals passed CAPD screening and do not require CAP test. Although no subject in the present study reached this score, it was possible to observe the self-improvement of the subject after having undergone rehabilitation through the ACAT. This result stems from the majority of subjects who underwent treatment and did not reach normal standards in all behavioral tests of CAP reevaluation. Anyway, their percentage of correct answers increased and patients felt improvement in auditory and attentional aspects. This result can also be justified by the nature of auditory processing disorders, which for the most part also involve aspects of expressive and receptive language. This result reinforces the complementary role that ACAT plays in the rehabilitation of CAPD, contributing to the improvement in aspects of attention, memory and concentration. Other manifestations, not always auditory, need a more specific approach nevertheless; the fact is that even with the occurrence of an increase in the score, no case reached 56 points in the total score. 
There is currently no specific questionnaire in Brazil to be applied as a subjective measure after the ACAT. SAB was developed as a screening tool for CAPD. In this sense, the present study can demonstrate a new clinical application for the instrument, since the participants already had CAPD diagnosed by behavioral tests and the questionnaire was used to demonstrate the impact that acoustically controlled auditory training had on auditory, academic behaviors and attention under the judgment of the patients and / or their families.

\section{CONCLUSION}

After a critical analysis of the results of the present study, it is possible to conclude that the subjective perception of the individuals and their family members could be identified by the application of SAB in the pre and post ACAT evaluations, revealing improvement in auditory and attention behaviors.

\section{ACKNOWLEDGEMENTS}

To Fundação para Pesquisa do Estado de São Paulo (FAPESP) for the promotion and feasibility of this study. Grant 2014 / 19827-5.

\section{REFERENCES}

1. Musiek FE, Shinn J, Hare C. Plasticity, auditory training, and auditory processing disorders. Semin Hear. 2002;23(4):263-75.

2. Chermak GD. Neurobiological connections are key to APD. Hear J. 2004;57(4):58-9.

3. American Speech-Language Hearing Association. (Central) Auditory Processing Disorders [Technical Report]. ASHA. 2005. [citado 2016 Jan 20] Disponível em: http://www.phon.ucl.ac.uk/courses/ spsci/audper/ASHA\%202005\%20CAPD\%20 statement.pdf

4. Samelli AG, Mecca FFDN. Treinamento auditivo para transtorno do processamento auditivo: Uma proposta de intervenção terapêutica. Rev. CEFAC. 2009;12(2):235-41.

5. Musiek F. Habilitation and management of auditory processing disorders: overview of selected procedures. J Am Acad Audiol. 1999;10(6):329-42.

6. Zalcman TE, Schochat E. A eficácia do treinamento auditivo formal em indivíduos com transtorno de processamento auditivo. Rev Soc Bras Fonoaudiol. 2007;12(4):310-4.

7. Cox RM, Alexander GC. The abbreviated profile of hearing aid benefit. Ear Hear. 1995;16(2):176-83.
8. Ventry IM, Weinstein BE. The Hearing Handicap Inventory for the eldertly: a new tool. Ear Hear. 1982;3(3):128-34.

9. Cibian AP, Pereira LD. Questionnaire for use in the monitoring of auditory training results. Distúrb. Comun. 2015;27(3):470-82.

10. Volpatto FL, Rechia IC, Lessa AH, Soldera CL, Ferreira MI, Machado MS. Questionnaires and checklists for central auditory processing screening used in Brazil: a systematic review. Braz J Otorhinolaryngol. 2019;85(1):99-110.

11. O'Hara B, Mealings K. Developing the auditory processing domains questionnaire (APDQ): a differential screening tool for auditory processing disorder. Int J Audiol. 2018;57(10):764-75.

12. Yokoyama $\mathrm{CH}$, Dias KZ, Pereira LD. Questionário de domínios de processamento auditivo (APDQ): versão em português [Monografia]. São Paulo (SP): Universidade Federal de São Paulo - UNIFESP, Departamento de Fonoaudiologia, Curso de Especialização em Audiologia; 2015.

13. Martins KVC, Pereira LD, Ziliotto K. Investigação de comportamentos auditivos por meio de questionário [Monografia]. São Paulo SP): Universidade Federal de São Paulo - UNIFESP, Departamento de Fonoaudiologia, Curso de Especialização em Audiologia; 2015.

14. Tye-Murray N, Sommers MS, Mauzé E, Scroy C, Barcroft J, Spehar B. Using patient perceptions of relative benefit and enjoyment to assess auditory training. J Am Acad Audiol. 2012;23(8):623-34.

15. Nunes CL, Pereira LD, Carvalho GS. Scale of auditory behaviors and auditory behavior tests for auditory processing assessment in Portuguese children. CoDAS. 2013;25(3):209-15.

16. Northen JL, Downs MP. In: __ Hearing in children. 6a.ed. San Diego: Plural Publishing Inc; 2014. p. 89-90.

17. Pereira LD. Avaliação do processamento auditivo central. In: Lopes Filho $\mathrm{O}$ (org). Tratado de fonoaudiologia. São Paulo: Roca; 1997a. p. 109-26.

18. King AJ. Auditory perception: does practice make perfect? Curr Biol. 1999;9(4):R143-6.

19. Agnew JA, Dorn C, Eden GF. Effect of intensive training on auditory processing and reading skills. Brain Lang. 2004;88(1):21-5.

20. Jerger J, Musiek F. Report of the Consensus Conference on the diagnosis of auditory processing disorders in school-aged children. J Am Acad Audiol. 2000;11(9):467-74. 
21. Tallal P, Miller SL, Bedi G, Byma G, Wang X, Nagarajan $S S$ et al. Language comprehension in language-learning impaired children improved with acoustically modified speech. Science. 1996;271(5245):81-4.

22. Putter-Katz H, Said LAB, Feldman I, Miran D, Kushnir D, Muchnik $C$ et al. Treatment and evaluation indices of auditory processing disorders. Semin Hear. 2002;23(4):357-64.

23. Garcia VL, Pereira LD, Fukuda Y. Atenção seletiva: PSI em crianças com distúrbio de aprendizagem. Rev Bras Otorrinolaringol. 2007;73(3):404-11.

24. Musiek F, Schochat E. Auditory training and central auditory processing disorders. Semin Hear. 1998;19(4):354-65.

25. Gil D. Treinamento auditivo formal em adultos com deficiência auditiva [Tese]. São Paulo (SP): Universidade Federal de São Paulo; 2006.

26. Stroiek S, Quevedo LS, Kieling CH, Battezini ACL. Auditory training in auditory processing disorders: a case study. Rev. CEFAC. 2015;17(2):604-14.

27. Cibian AP, Pereira LD. Questionnaire for use in the monitoring of auditory training results. Distúrb. Comun. 2015;27(3):470-82.

28. Lucas PA, Zacare CC, Alves Filho OC, Amantini RCB, Bevilacqua MC, Zaidan E. Scan: perfil de desempenho em crianças de sete e oito anos. Pró-Fono R Atual Cient. 2007;19(4):370-3.

29. Sharma M, Purdy SC, Kelly AS. Comorbidity of auditory processing, language, and reading disorders. J Speech Lang Hear Res. 2009;52(3):706-22.

30. Frota S, Pereira LD. Processamento auditivo: estudo em crianças com distúrbios da leitura e da escrita. Rev. Psicopedag. 2010;27(83):214-22.

31. Machado CSS, Valle HLBS, Paula KM, Lima SS. Caracterização do processamento auditivo das crianças com distúrbio de leitura e escrita de 8 a 12 anos em tratamento no centro clínico de fonoaudiologia da Pontifícia Universidade Católica de Minas Gerais. Rev. CEFAC. 2011;13(3):504-12.

32. Soares AJC, Sanches SGG, Alves DC, Carvallo RMM, Cárnio MS. Temporal auditory processing and phonological awareness in reading and writing disorders: preliminary data. CoDAS. 2013;25(2):188-90.

33. Signor RCF, Vieira SKV, Berberian AP, Santana AP. Auditory processing disorder $x$ reading and writing difficulty: is there a relationship? Rev. Bras. Linguíst. Apl. 2018;18(3):581-607. 